\title{
The reproductive tract of the male spiny mouse (Acomys cahirinus) and coagulation studies with other species
}

\author{
Betsy Peitz, D. Foreman* and M. Schmitt* \\ Department of Biology, California State University Los Angeles, California 90032, and \\ *Department of Biology, Case Western Reserve University, Cleveland, Ohio 44106, U.S.A.
}

\begin{abstract}
Summary. The testes of the spiny mice showed asymmetry, the left being significantly heavier than the right $(P=0.025)$. Histological studies indicated that spermatozoa were first present in the testes of animals 35-45 days of age but the maturation of the accessory glands, especially the lateral prostates and coagulating glands, occurred later. The highest fructose concentration in the adult was in the lateral prostates $(126.97 \pm 22.23 \mathrm{mg}$ fructose $/ 100 \mathrm{~g}, n=5)$ and coagulating glands $(99.38 \pm 17.65 \mathrm{mg}$ fructose $/ 100 \mathrm{~g}$ gland weight, $n=5)$. Coagulation tests of mixtures of extracts of seminal vesicles and coagulating glands from spiny mice and rats indicated that the vesiculase of the spiny mouse was active on rat substrates and vice versa. Cross-reactions of extracts of house mouse (Mus musculus), hamster (Mesocricetus auratus), gerbil (Meriones unguiculatus), and guinea-pig (Cavia porcellus) seminal vesicles (substrate) and coagulating glands (vesiculase) with those of rats and spiny mice showed that although the substrates of rat and spiny mouse were readily coagulated by vesiculase from all the other species, rat and spiny mouse vesiculase were not equally active on substrates of the other species.
\end{abstract}

\section{Introduction}

The spiny mouse (Acomys cahirinus, Family Muridae) is a small rodent found in the deserts of the Near East. The species was originally brought into the laboratory because of its special adaptations to desert life, including its ability to concentrate urine and to maintain blood volume during dehydration (Shkolnik \& Borut, 1969; Horowitz \& Borut, 1970). Maternal behaviour and "mid-wife" behaviour by other females in the same cages as mothers giving birth were described by Dieterlen (1962). The oestrous cycle of female spiny mice has been studied; it lasts approximately 11 days and a functional corpus luteum develops after ovulation in the absence of mating (Peitz, 1975). The accessory glands of the male reproductive system have not been described for this species and there have been no reports on their function(s). This study includes a survey of the weights and normal histology of the organs of the male reproductive tract as well as determinations of fructose content and coagulation reactions of the fluids of the accessury glands.

\section{Materials and Methods}

The spiny mice used in this study were taken from a breeding colony started in 1968 with animals collected in Israel by $\mathbf{A}$. Shkolnik. The animals were housed in wooden cages of two sizes: $36 \times 49 \times 28 \mathrm{~cm}$ and $49 \times 74 \times 28 \mathrm{~cm}$. The number of animals in each cage was 
dependent on the breeding activity of the group. The larger cages had 16-40 animals while the smaller cages had 6-18. The diet was sunflower seeds, rolled toasted barley, dried shelled corn and Purina Cat Chow. Water was available at all times. The temperature was maintained at $22.5^{\circ} \mathrm{C}$ and the lighting was $12 \mathrm{~h}$ light $/ 24 \mathrm{~h}$. Under these conditions, these mice can live for at least 4 years.

Tissues from the reproductive tracts of normal males were weighed on a Roller Smith torsion balance to the nearest $0.1 \mathrm{mg}$ and fixed in Bouin's solution for histological studies. The paraffin-wax sections were cut at $10 \mu \mathrm{m}$ and stained with haematoxylin and eosin.

A total of 108 animals of various ages was used. Of these, 23 were used to determine weight differences between the right and left testes. In all others, total testis weight was determined by weighing the testes together. The accessory glands of 46 males of various ages were assayed for fructose by a modified Roe procedure (Foreman, Gaylor, Evans \& Trella, 1973) which measures both fructose and fructose phosphates. The tissues from 17 males were used for histological preparations.

Seven male spiny mice were used in coagulation studies. The slide test of Zorgniotti \& Brendler (1957) was used for intraspecies and interspecies reactions. Four rats (Rattus norvegicus), 2 gerbils (Meriones unguiculatus), 2 hamsters (Mesocricetus auratus), 8 house mice (Mus musculus) and one guinea-pig (Cavia porcellus) were used to provide accessory sex gland secretions for the interspecific studies. The seminal vesicle fluid of rats and hamsters was taken up in a syringe and $0.1 \mathrm{ml}$ was added to $1.0 \mathrm{ml}$ saline $(9 \mathrm{~g} \mathrm{NaCl} / 1)$. The contents of the glands of other species were expressed directly into saline because of their small size or the viscosity of the fluids. Seminal vesicles of 4 house mice were pooled in $1.5 \mathrm{ml}$, those of spiny mice and gerbils were placed in $1.0 \mathrm{ml}$, and those of the guinea-pig in $4 \mathrm{ml}$. Coagulating glands weighing $<50 \mathrm{mg}$ were homogenized in $0.5 \mathrm{ml}$ saline (spiny mouse, gerbil), those weighing $>50$ $\mathrm{mg}$ were placed in $1.0 \mathrm{ml}$ (hamster) or $2.0 \mathrm{ml}$ (guinea-pig and rat). Coagulating glands from 4 mice were pooled and homogenized in $0.5 \mathrm{ml}$ saline. Lateral prostates and ventral prostates of 5 spiny mice were pooled and homogenized in $0.5 \mathrm{ml}$ saline to test intra-species reactions. The extracts were tested by mixing equal quantities ( 1 drop each from a Pasteur pipette) together on a microscope slide, observing flocculation and timing the appearance of coagulation (coagulation time).

\section{Observations}

Testis weight was correlated with body weight in immature and mature males. The graph of testis weight against body weight was a curve, but the slope changed sharply at about $45 \mathrm{~g}$ body weight, so two straight lines were fitted to these data by the method of least squares. The best fitting equation for animals weighing $45 \mathrm{~g}$ or less is $y=14 \cdot 2 x-242(r=0.687, \mathrm{~N}=47)$. The equation for animals over $45 \mathrm{~g}$ is $y=4.96 x+130.7(r=0.705, \mathrm{~N}=61)$. Testis weight increased rapidly before puberty and continued increasing at a slower rate in mature males. There was also strong evidence of testicular asymmetry because in 23 normal adult males the left testis $(258.8 \pm 6.0$ (s.e.m.) $\mathrm{mg}$ ) was significantly heavier than the right $(245.0 \pm 7.0 \mathrm{mg} ; P=$ 0.025 ). Histological examination of testes showed that although spermatozoa were first present in the testes of animals 35 to 45 days old, the mature pattern of the spermatogenic cycle was not fully established in the seminiferous tubules at that time.

The reproductive tract of the adult male spiny mouse has an extensive array of accessory glands typical of many murids. These include seminal vesicles, coagulating glands, dorsal, lateral and ventral prostate glands and ampullary glands. The gross appearance of the male tract is different from that of other commonly used laboratory species because of the larger lateral prostates and very small ventral prostates which, in adults, may be very yellow (Text-fig. 1). Weights of accessory glands at various ages are given (Table 1). Seminal vesicles were grossly 
identifiable in young animals before the ventral prostate had developed enough to be seen. The seminal vesicles appeared to grow at a constant rate in sexually mature animals and some 80$100 \mathrm{~g}$ animals had seminal vesicles as heavy as $450-500 \mathrm{mg}$. At a body weight of $23 \mathrm{~g}$, the fructose concentration of the seminal vesicles was $240 \mathrm{mg} / 100 \mathrm{~g}$ tissue but fell to adult levels as the glands grew (Table 1). A similar trend was found in the fructose values of the ventral prostate. Lateral prostates and coagulating glands were later in developing and were not dissectable until the young males weighed $29 \mathrm{~g}$ or more (35-50 days of age). The highest concentration of fructose was found in the lateral prostate and coagulating glands in adult males (Table 1).

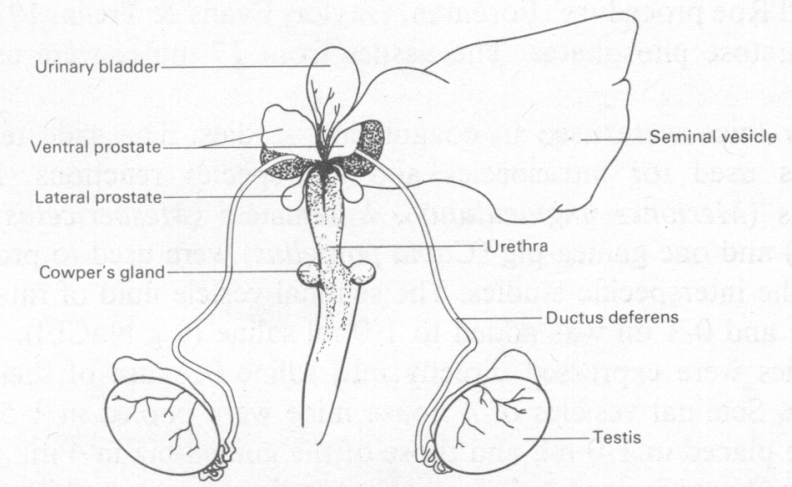

Text-fig. 1. Diagram of the ventral aspect of the reproductive tract of the male spiny mouse (Acomys cahirinus) to show the proportional size and location of the ventral and lateral prostate glands. The dorsal prostate is not shown, being similar to that of the rat. (Drawn by Dora Staneff.)

Table 1. Fructose concentrations (mg fructose/100 g gland) in the accessory glands of male spiny mice

\begin{tabular}{|c|c|c|c|}
\hline & \multicolumn{3}{|c|}{ Males } \\
\hline & Young & Young adult & Mature adult \\
\hline No. & 24 & 11 & 5 \\
\hline Body wt (g) & $30.60 \pm 0.72$ & $55.28 \pm 3.58$ & $75 \cdot 50 \pm 8.47$ \\
\hline Wt of paired testes (mg) & $198.22 \pm 22.47$ & $395.20 \pm 33.89$ & $512.00 \pm 28.18$ \\
\hline \multicolumn{4}{|l|}{ Seminal vesicle } \\
\hline Wt (mg) & $70.07 \pm 15.38$ & $180 \cdot 50 \pm 31 \cdot 90$ & $271 \cdot 12 \pm 36.62$ \\
\hline Fructose (mg) & $103.30 \pm 16.6$ & $38.52 \pm 3.96$ & $45.56 \pm 10.98$ \\
\hline \multicolumn{4}{|l|}{ Dorsal prostate } \\
\hline $\mathrm{Wt}(\mathrm{mg})$ & $11.64 \pm 1.82$ & $34 \cdot 35 \pm 4 \cdot 58$ & $52.00 \pm 11.44$ \\
\hline Fructose (mg) & $258.52 \pm 37 \cdot 1$ & $86.57 \pm 8.86$ & $78.94 \pm 18.36$ \\
\hline \multicolumn{4}{|l|}{ Ventral prostate } \\
\hline $\mathrm{Wt}(\mathrm{mg})$ & $8.58 \pm 1.42$ & $22.66 \pm 3.08$ & $37.76 \pm 4.93$ \\
\hline Fructose (mg) & $343.60 \pm 48.9$ & $55.07 \pm 4.55$ & $47 \cdot 10 \pm 4.60$ \\
\hline \multicolumn{4}{|l|}{ Lateral prostate } \\
\hline Wt (mg) & - & $12 \cdot 27 \pm 1 \cdot 33$ & $18.58 \pm 1.02$ \\
\hline Fructose (mg) & - & $106.01 \pm 7.18$ & $126.97 \pm 22.23$ \\
\hline \multicolumn{4}{|l|}{ Coagulating gland } \\
\hline $\mathrm{Wt}(\mathrm{mg})$ & $11.24+0.95$ & $12.52 \pm 1.38$ & $29.46 \pm 4.41$ \\
\hline Fructose (mg) & $205.90 \pm 50.65$ & $150.31 \pm 15.48$ & $99.38 \pm 17.65$ \\
\hline
\end{tabular}


Histological observations showed that adult accessory glands resembled those of the house mouse and rat. The seminal vesicle of the spiny mouse had tall columnar epithelium with eosinophilic granules in the apical region similar to that seen in the mouse but the cytoplasm surrounding the nucleus appeared generally more basophilic than that of the mouse. The ventral prostate had tall columnar cells with basal nuclei and strong cytoplasmic basophilia near the nuclei rather than in the apical region as is typical of the rat. The coagulating gland and dorsal prostate glands of the spiny mice were very similar in structure. They both had cuboidal to tall columnar epithelium and produced an eosinophilic secretion in membrane bound vesicles. The nuclei of the dorsal prostate were more basal than those of the coagulating gland. The cells tended to be more columnar and the cytoplasm more basophilic in the coagulating gland than in the dorsal prostate. The ampullary glands had columnar epithelium in the acini and ducts with a cuboidal epithelium. The histology of the lateral prostate resembled that of the ventral prostate gland except that the epithelium appeared to be taller. Very little secretion stained in the acini. Most dissections of the lateral prostates had small areas of adhering coagulating gland because the ducts of these glands were close together. Our studies of the time of the appearance of secretory materials in the lumina of the various accessory glands and the growth of these glands to adult weight ranges suggested that puberty in the young male spiny mouse occurred at about 50 $\mathrm{g}$ body weight at an age of 55-65 days. This was later than the first appearance of spermatozoa in the testis tubules.

\section{Coagulation studies}

Spiny mouse seminal vesicle fluid (substrate) was readily coagulated by coagulating gland extract (vesiculase) (Table 2). It appeared to be very active when not diluted because coagulation times could not be taken. Traumatic killing procedures, such as cervical dislocation, tended to produce contractions of the male reproductive tract which caused mixing of fluids within the tract and the seminal vesicles were often coagulated when the animal was opened. Dilutions of ventral and lateral prostates similar to those of the coagulating gland produced flocculation but not coagulation of seminal vesicle fluid. When 4 pairs of lateral prostates were pooled they coagulated seminal vesicle fluid in $5.7 \pm 0.1$ (s.d.) sec $(\mathrm{N}=6)$. Similarly, 4 pairs of ventral prostates also coagulated substrate $(9 \cdot 0 \pm 0.1 \mathrm{sec}, \mathrm{N}=6)$.

Cross-reactions of spiny mouse with rat seminal vesicle fluid and coagulating gland extract were undertaken to determine which glands had vesiculase. Neither lateral nor ventral prostates reacted in lower concentrations but both were active at higher concentrations on rat substrate $(21.0 \pm 6.2 \mathrm{sec}, \mathrm{N}=4$, for combined extracts with rat substrate). Spiny mouse vesiculase was active on rat substrate and the rat enzyme was very active on spiny mouse substrate (Table 2). The results with a variety of other rodent species are also given in Table 2 . The variations within individual animals in each species are doubtless due to differences in sexual maturity, effects of recent mating and possibly genetic differences. In spite of these variations, some generalizations were possible: rat vesiculase was active on all species and all species had vesiculase that coagulated rat substrate. The rat vesiculase was less active on house mouse and guinea-pig substrate than on other substrates. Similarly, all vesiculases from other species coagulated spiny mouse substrate but spiny mouse vesiculase, while active with rat and gerbil substrates, reacted very slowly with hamster substrate and had no reaction with house mouse or guinea-pig substrates (Table 2).

\section{Discussion}

Although some of the accessory glands of male spiny mice were quite different in gross appearance from those of other laboratory rodents, they had rather similar histology. Fructose concentrations were highest in those glands of spiny mice that develop as prostatic lobes. Thus, the lateral prostate, dorsal prostate and coagulating gland (craniodorsal prostate) had the 
Table 2. Coagulation time in seconds of cross-reactions of diluted seminal vesicle (SV) fluid (substrate) and extracts of coagulating glands (CG) (enzymes) within and between species

\begin{tabular}{|c|c|c|c|c|c|c|}
\hline \multirow[b]{2}{*}{ Species } & \multirow[b]{2}{*}{ Glands } & \multirow{2}{*}{$\begin{array}{l}\text { Intra-species } \\
\text { reactions }\end{array}$} & \multicolumn{2}{|c|}{$\begin{array}{l}\text { Interspecies reactions } \\
\text { with rat }\end{array}$} & \multicolumn{2}{|c|}{$\begin{array}{l}\text { Interspecies reactions } \\
\text { with spiny mouse }\end{array}$} \\
\hline & & & SV & CG & SV & $\mathrm{CG}$ \\
\hline \multirow[t]{2}{*}{ Rat } & SV & $\begin{array}{r}3.9 \pm 1.2(5) \\
11 \pm 1.4(4)\end{array}$ & & & & \\
\hline & CG & $\begin{array}{r}11 \pm 0.1(3) \\
8 \cdot 5 \pm 1 \cdot 3(4)\end{array}$ & & & & \\
\hline \multirow[t]{2}{*}{ Spiny mouse } & sV & $\begin{array}{r}8 \cdot 7 \pm 1 \cdot 3(4) \\
17 \cdot 0 \pm 2 \cdot 2(4)\end{array}$ & & $\begin{array}{r}16 \cdot 6 \pm 0.9(6) \\
18 \cdot 2 \pm 3 \cdot 4(4) \\
5 \cdot 7 \pm 1 \quad(4) \\
6 \cdot 2 \pm 5 \quad(4) \\
7.0 \pm 1 \cdot 2(4)\end{array}$ & & \\
\hline & $\mathrm{CG}$ & $\begin{array}{l}14 \cdot 0 \pm 0 \quad(3) \\
25 \cdot 2 \pm 2 \cdot 5(4) \\
28 \cdot 1 \pm 1 \cdot 1(5)\end{array}$ & $\begin{array}{l}13.2 \pm 2.5(4) \\
11.5 \pm 1.7(4) \\
17.2 \pm 3.6(4) \\
27.7 \pm 5.9(4)\end{array}$ & & & \\
\hline \multirow[t]{2}{*}{ House mouse } & e SV & $\begin{array}{l}26 \cdot 2 \pm 2 \cdot 6(4) \\
38 \cdot 0 \pm 3 \cdot 6(4)\end{array}$ & & $\begin{array}{l}48 \cdot 7 \pm 5 \cdot 8(4) \\
40 \cdot 0 \pm 3 \cdot 3(4)\end{array}$ & & $\begin{array}{l}\text { NR (4) } \\
\text { NR (2) }\end{array}$ \\
\hline & $\mathrm{CG}$ & & $\begin{array}{l}6.7 \pm 0.5(4) \\
6.5 \pm 1.0(4)\end{array}$ & & $\begin{array}{r}16 \cdot 3 \pm 2.5(3) \\
6.7 \pm 1 \cdot 0(4)\end{array}$ & \\
\hline \multirow[t]{2}{*}{ Hamster } & SV & $\begin{array}{l}5.7 \pm 0.5(4) \\
6.2 \pm 1.0(4)\end{array}$ & & $8 \cdot 5 \pm 1 \cdot 0(4)$ & & $56 \cdot 6 \pm 14 \cdot 6(7)$ \\
\hline & CG & & $\begin{array}{l}8.0 \pm 1.2(4) \\
4.7 \pm 1.0(4)\end{array}$ & & $\begin{aligned} 10 \cdot 7 & \pm 1 \\
5 \cdot 2 & \pm 1 \cdot 2(4)\end{aligned}$ & \\
\hline \multirow[t]{2}{*}{ Gerbil } & SV & $\begin{array}{l}8.2 \pm 1.3(4) \\
6.7 \pm 1.0(4)\end{array}$ & & $\begin{array}{l}5 \cdot 2 \pm 1 \cdot 0(4) \\
8 \cdot 5 \pm 1 \cdot 2(4)\end{array}$ & & $\begin{aligned} 8 \cdot 0 \pm 4 \cdot 3(4) \\
19 \cdot 0 \pm 0\end{aligned}$ \\
\hline & $\mathrm{CG}$ & & $\begin{array}{l}5 \cdot 2 \pm 1 \cdot 9(4) \\
6 \cdot 3 \pm 1 \cdot 0(4)\end{array}$ & & $\begin{array}{l}7.2 \pm 1.0(4) \\
4.5 \pm 0.6(4)\end{array}$ & \\
\hline \multirow[t]{2}{*}{ Guinea-pig } & SV & $19.2 \pm 3 \cdot 0(6)$ & & $42.7 \pm 3.4(4)$ & & NR (2) \\
\hline & CG & & $4.7 \pm 0.5(4)$ & & $7.2 \pm 0.5(4)$ & \\
\hline
\end{tabular}

Each mean \pm s.d. is the value from a single preparation for the number of replicates indicated in parentheses. At least 2 preparations were usually tested for each cross-reaction. NR $=$ no reaction.

highest values. In this respect, the distribution of fructose was similar to that found in the rat and prairie dog (Foreman, 1974). As in the rat, the seminal vesicles and prostates had high fructose concentrations early in development. These values dropped to normal as puberty approached.

Coagulation studies have been done in several ways. Walker (1910) mixed undiluted fluids of guinea-pig and rat seminal vesicles and coagulating glands to identify the coagulating gland in each species. In these undiluted samples coagulation occurred immediately. Gotterer, Ginsberg, Schulman, Banks \& Williams-Ashman, (1955) used acetone extracts of seminal vesicle and coagulating gland fluids and determined "coagulation" by turbidimetric measurements. This method is more tedious, requires larger gland volumes and takes a longer time for a reaction to be measured than the method we used (Zorgniotti \& Brendler, 1957). We consider that the 
reaction rates measured by the method which we used are a more realistic reflection of the coagulation reaction than those reported by Gotterer et al. (1955).

Our coagulation studies showed that the spiny mouse has a true coagulating gland because its extracts react with rat seminal vesicle fluid. Also it apparently has some enzymes active in coagulation in both the lateral and ventral prostates, although the concentration of enzyme in these glands is lower than that in the coagulating glands. It is not unusual for glands other than the seminal vesicles and coagulating glands to be involved in coagulation. Cowpers' gland has been shown to be involved in semen coagulation in the rat (Hart \& Greenstein, 1968).

The species cross-reactions given here show that while rat and spiny mouse substrates are readily coagulated by enzymes of all species tested, the vesiculase of the rat and spiny mouse are not as active on the substrates of other species. This suggests that the substrates of the other species differ from one another more than the enzymes. A previous study has shown that no cross-reactions occurred between prairie dog dorso-lateral prostate or dorsal prostate and rat seminal vesicles or coagulating glands (Foreman, 1974). These results indicate that different degrees of cross-reactivity occur between species and suggest that cross-coagulation studies with more species could be informative.

\section{References}

Dieterlen, F. (1962) Geburt und geburtshilfe bei der Stachelmaus Acomys cahirinus. Z. Tierpsychol. 19, 191-222.

Foreman, D., Gaylor, L., Evans, E. \& Trella, C. (1973) A modification of the Roe procedure for determination of fructose in tissues with increased specificity. Analyt. Biochem. 56, 584-590.

Foreman, D. (1974) Structural and functional homologies of the accessory reproductive glands of two species of sciurids, Cynomys ludovicianus and Citellus tridecemlineatus, Anat. Rec. 180, 331-340.

Gotterer, G., Ginsberg, D., Schulman, T., Banks, J. \& Williams-Ashman, H.G. (1955) Enzymatic coagulation of semen. Nature Lond. 176, 12091211.

Hart, R.G. \& Greenstein, J.S. (1968) A newly discovered rôle for Cowpers' gland secretion in rodent semen coagulation. J. Reprod. Fert. 17, 87-94.
Horowitz, M. \& Borut, A. (1970) Effect of acute dehydration on body fluid compartments in three rodent species, Rattus norvegicus, Acomys cahirinus and Meriones crassus. Comp. Biochem. Physiol. 35, 283-290.

Peitz, B. (1975) Changes in total body water and the biological half life of water during the estrous cycle in rats, spiny mice and prairie dogs. Doctoral dissertation, Case Western Reserve University.

Shkolnik, A. \& Borut, A. (1969) Temperature and water relations in two species of spiny mice (Acomys). $J$. Mammal. 50, 245-255.

Walker, G. (1910) A special function discovered in glandular structures hitherto supposed to form a part of the prostate gland in rats and guinea pigs. Johns Hopkins Hosp. Bull. 21, 182-185.

Zorgniotti, A.W. \& Brendler, H. (1957) Studies in semen coagulation. Proc. Soc. exp. Biol. Med. 96, 195-197.

Received 31 January 1979 